\title{
Estratégia\&Negócios
}

ISSN 1984-3372

http://www.portaldeperiodicos.unisul.br/index.php/EeN/

\section{O PROCESSO DE IMPLEMENTAÇÃO DA GESTÃO ESTRATÉGICA DE CUSTOS EM UMA EMPRESA ESTATAL DE ENERGIA ELÉTRICA}

\section{THE IMPLEMENTATION PROCESS OF THE STRATEGIC MANAGEMENT ACCOUNTING IN A STATE ELECTRIC POWER COMPANY}

\section{Sabrina Weiss Raupp}

Mestrado em Administração pela Universidade Federal de Santa Catarina - UFSC.

E-mail: sabrinaraupp@yahoo.com.br

\section{Altair Borgert}

Professor do Departamento de Ciências Contábeis da Universidade Federal de Santa Catarina -UFSC. Doutor em Engenharia de Produção pela UFSC.

E-mail: borgert@cse.ufsc.br

\section{Patrícia Nunes}

Professora da Universidade do Sul de Santa Catarina - UNISUL para os cursos de Administração e Ciências Contábeis. Mestre em Ciências Contábeis pela Universidade Federal de Santa Catarina - UFSC.

E-mail: patricia contabeis@hotmail.com

\section{Mara Juliana Ferrari}

Professora do Centro Universitário Para o Desenvolvimento do Alto Vale do Itajaí - UNIDAVI. Mestranda do Programa de Pós-Graduação em Contabilidade da Universidade Federal de Santa Catarina - UFSC.

E-mail: mara@rossa.com.br

Recebido em 02/02/2012. Aprovado em 18/04/2012. Disponibilizado em 25/05/2012. Avaliado pelo Sistema double blind review

R. eletr. estrat. neg., Florianópolis, v.5, n.1, p. 137-166, jan./abr. 2012 http://portaldeperiodicos.unisul.br/index.php/EeN/index
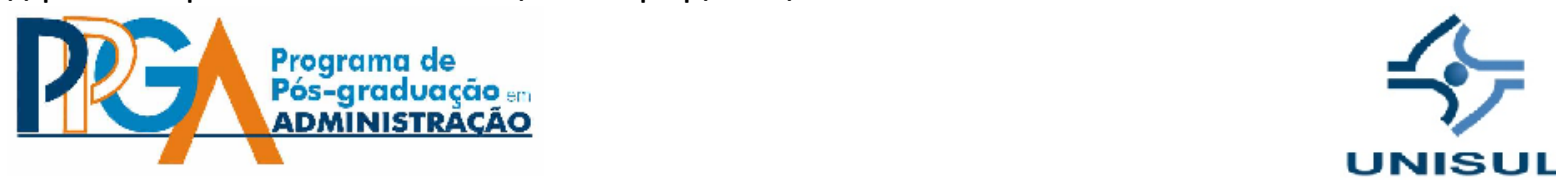

(C) Copyright 2008 UNISUL-PPGA/Estratégia e Negócios. Todos os direitos reservados. Permitida citação parcial, desde que identificada a fonte. Proibida a reprodução total. Em caso de dúvidas, consulte o editor: ademar.unisul@gmail.com; (48) 3229-1932 


\section{RESUMO}

O presente artigo tem como objetivo investigar a aderência do modelo de Gestão Estratégica de Custos (GEC) implementado em uma empresa estatal de energia elétrica ao modelo proposto por Shank e Govindarajan, sob a ótica dos gestores e empregados. São considerados dez fatores, internos e externos à organização, derivados de três temas centrais: análise da cadeia de valor, análise do posicionamento estratégico e análise dos direcionadores de custos. O estudo de caso possui características descritivas, de natureza qualitativa, cuja coleta de dados se baseia em entrevista semiestruturada, levantamento e observação participante, aplicado na Eletrosul Centrais Elétricas S.A., especificamente na área de "gestão do processo de GEC". Para tal, foi realizada a análise de conteúdo das informações levantadas nos documentos formais e comparadas com o praticado (identificado nas entrevistas). Concluiu-se que o modelo de GEC já foi implementado parcialmente na Empresa e existe certo consenso entre os entrevistados dos três níveis hierárquicos de que: i) a análise da cadeia de valor concentra fatores que facilitam e, ao mesmo tempo, dificultam a implementação do modelo; ii) a análise do posicionamento estratégico concentra os fatores que estão mais estruturados; e iii) a análise dos direcionadores de custos concentra os fatores que mais dificultam a completa implementação da GEC.

Palavras-chave: Gestão Estratégica de Custos. Cadeia de valor. Setor elétrico.

\section{INTRODUÇÃO}

O termo Gestão Estratégica de Custos (GEC) é utilizado para designar a conexão entre a gestão de custos e a gestão estratégica da organização de forma a gerar vantagem competitiva num ambiente de negócios globalizado e competitivo. Residem, justamente, na integração da análise dos custos com os direcionamentos estratégicos das entidades, as 
contribuições que se podem apresentar como resultado de tal conexão. A adoção desta concepção implica a utilização de uma abordagem que visa à melhoria contínua do desempenho e se torna de maior relevância para a tomada de decisão, em relação às abordagens tradicionais de custos. (MAHER, 2001).

Neste sentido, as empresas do setor elétrico brasileiro têm demonstrado interesse na implantação da gestão estratégica dos custos, pois, conforme Santos, Schmidt e Pinheiro (2006), os gestores empresariais buscam instrumentos gerenciais para a produção de informações estratégicas que possam criar e desenvolver vantagem competitiva sustentável. Assim, uma das formas para garantir a continuidade operacional e o fortalecimento do posicionamento da empresa no mercado é a aplicação das técnicas da GEC.

O setor elétrico compreende o conjunto de atividades relacionadas com geração, transmissão, distribuição e comercialização de energia elétrica. Neste setor, a competição ganhou força a partir da década de 1990, quando começou a ser implantado o modelo de regulação, cujo objetivo era promover a competição nos segmentos de geração e comercialização e aumentar o grau de eficiência setorial. Naquele momento, havia a necessidade de investimento na matriz energética brasileira, no sentido de ampliação e melhoria da sua confiabilidade. Para tal, buscou-se diminuir a atuação do Estado por meio de incentivos aos investimentos privados e por meio das privatizações. No entanto, esse modelo provocou uma série de obstáculos que põem à prova a competição em longo prazo das empresas estatais que atuam no setor elétrico. Diante deste cenário, fica o desafio de trabalhar em busca da eficiência operacional, com a otimização da aplicação de recursos e a redução de perdas.

Outro complicador para as empresas deste setor, em particular as transmissoras, está na forma de cálculo da sua principal receita, oriunda da Receita Anual Permitida (RAP) e determinada em função de contratos de serviços de transmissão. A maior parte desta receita é fixa, com tendência a reduzir em função das revisões tarifárias e da parcela variável por indisponibilidade, previstas no contrato de concessão. Com isso, resta às transmissoras, como alternativa para a maximização dos seus resultados, a gestão (controle e redução) dos 
seus gastos e a expansão dos seus ativos.

Uma das empresas do setor elétrico que vivencia esta problemática é a Eletrosul Centrais Elétricas S.A., uma sociedade anônima de capital fechado e economia mista, concessionária de serviço público de transmissão e geração de energia elétrica (ELETROSUL, 2009a). Dessa forma, a Empresa foi escolhida como objeto de estudo por ter vivenciado as diversas etapas previstas no novo modelo do setor elétrico, sendo a única empresa que teve seu parque de geração privatizado na forma como apregoava o modelo que vigorou entre 1996 e 2004. Além disso, teve um desempenho satisfatório no primeiro processo de revisão tarifária, no qual seus custos foram analisados pelo órgão regulador para a definição de um novo preço das tarifas de energia.

Em seu Plano Estratégico, elaborado em 2007, a Eletrosul fez uma previsão para a implementação da GEC como base para o desenvolvimento de suas estratégias empresariais, de forma a proporcionar competitividade e sustentabilidade (ELETROSUL, 2009a). No entanto, apesar de várias práticas já terem sido adotadas, o modelo não foi totalmente implementado. Alguns fatores, internos ou externos à organização, delimitam o tema e, portanto, precisam ser analisados de forma a potencializar a sua ação, para gerar vantagem competitiva e eliminar ou minimizar seu efeito dificultador.

Neste trabalho, o conjunto de fatores que interagem com o tema GEC são denominados como intervenientes, sobre os quais a organização pode ou não ter ingerência. A identificação dos fatores intervenientes se deu, primeiramente, por meio de pesquisa bibliográfica e estão organizados em três blocos: análise da cadeia de valores; análise do posicionamento estratégico; e análise dos direcionadores de custos. Não necessariamente, todos os fatores identificados como intervenientes estão relacionados nesta lista. Além disso, estão organizados por tema e não guardam qualquer ordem de priorização ou de ocorrência na organização.

A Gestão Estratégica de Custos possui várias formas de abordagem, as quais dependem de cada autor e em que se consideram aspectos e questões diferentes. Contudo, no presente trabalho, considera-se principalmente a abordagem de Shank e Govindarajan (1997). Então, com base na pesquisa bibliográfica e em entrevistas semiestruturadas, a 
pesquisa procura responder a seguinte questão: qual a aderência do modelo de gestão estratégica de custos implementado na Eletrosul, ao modelo proposto por Shank e Govindarajan, sob a ótica dos gestores e empregados? Portanto, como decorrência da presente problemática, o objetivo geral deste estudo é identificar, sob a ótica dos gestores e empregados, a aderência do modelo de gestão estratégica de custos implementado na Eletrosul ao modelo proposto por Shank e Govindarajan.

\section{GESTÃO ESTRATÉGICA DE CUSTOS}

A GEC surgiu para preencher as lacunas deixadas pela contabilidade gerencial no tocante à análise dos custos. Para Shank e Govindarajan (1997) e Langfield-Smith (2008), ela representa uma compreensão sofisticada da estrutura de custos de uma empresa, cujo entendimento tem por objetivo a busca de uma vantagem competitiva sustentável. Surgiu para atender às demandas mercadológicas quando, devido ao contexto de competitividade e de melhorias contínuas, as organizações buscam alternativas para suprir as necessidades advindas do mercado.

Os sistemas da GEC são componentes importantes para auxiliar na definição das estratégias das empresas, de modo a alcançar vantagem competitiva,e cujo gerenciamento dos custos requer um enfoque sistêmico, de forma a proporcionar uma visão mais ampla e externa à empresa. Assim, engloba a cadeia de valor completa do produto, que compreende não somente os fornecedores diretos, mas também os que estão atrás destes na cadeia produtiva, como os clientes diretos e até os consumidores finais.

Neste contexto, Nakagawa (2000) define a GEC como um sistema de planejamento e controle com o propósito de identificar os custos dos recursos consumidos para desempenhar atividades relevantes da empresa, determinar a eficiência e eficácia das atividades desempenhadas, identificar e avaliar as novas atividades que possam contribuir 
para as melhorias do desempenho da empresa no futuro e cumprir os objetivos em um ambiente caracterizado por mudanças tecnológicas.

Em termos de aplicação da GEC nas organizações, algumas pesquisas foram realizadas, como a de Machado et al. (2008), a qual tem o objetivo de identificar as práticas de gestão de custos com relação às suas prioridades estratégicas adotadas por empresas da indústria da construção civil no Estado do Paraná. Dentre elas, foram identificadas as seguintes: a) elaboração de planejamento com acompanhamento mensal dos resultados (real $x$ orçado), que é uma prática de gestão de custos adotada por empresas de pequeno porte com prioridades estratégicas de diferenciação; e b) elaboração de orçamento detalhado dos custos, por ocasião do planejamento de uma nova obra, que é prática adotada por empresas de médio porte com prioridade estratégica de enfoque. Nesta mesma direção, Souza, Silva e Pilz (2010), com o objetivo de investigar qual o efetivo uso de algumas das práticas de GEC em uma empresa brasileira multinacional, identificaram a preferência pelo uso de modelos tradicionais de gestão de custos, apesar de atuar com liderança em mercados competitivos, e concluem que estas características evidenciam um distanciamento em relação aos argumentos e conteúdos da literatura recente que trata da gestão de custos.

Já Gusmão e Almeida (2008) realizaram pesquisa com o objetivo de verificar se os gestores de empreendimentos hoteleiros de Curitiba e região metropolitana aplicam os conceitos de custos para desenvolver estratégias gerenciais voltadas às atividades de tomada de decisão. Seus achados apontam que, quanto ao posicionamento estratégico dos hotéis, predomina a estratégia de diferenciação para as atividades-fins como um todo. Por sua vez, foi significativa a percepção dos gestores em relação à utilidade das informações sobre custos operacionais, de fornecedores e de clientes para fins estratégicos.

Cinquini e Tenucci (2012) aplicaram pesquisa em empresas italianas com o objetivo de verificar, dentre outros aspectos, a aplicação das técnicas da GEC fundamentada em diversos autores. Concluíram que, dentre as 14 técnicas elencadas, sete apresentaram pontuação maior em relacão ao conjunto, com destaque para o Custeio de Atributos, Contabilidade de Clientes, Precificação Estratégica e Monitoramento da Posição Competitiva. Já a Mensuração Integrada de Desempenho e Custeio do Ciclo de Vida foram as 
técnicas menos utilizadas.

Contudo, Wrubel et al. (2011) destacam outra abordagem quanto aos estudos da GEC. Mesmo que seja objeto de várias pesquisas, principalmente em relação à aplicação nas organizações, ainda não há consenso por parte dos pesquisadores sobre os termos relacionados a esta temática. Neste sentido, propuseram uma categorização da GEC com base em três temas importantes definidos por Shank e Govindarajan (1997), quais sejam: a) análise da cadeia de valor; b) análise do posicionamento estratégico; e c) análise dos direcionadores de custos. A construção do referencial conceitual, ou da categorização, permite visualizar a relevância e assegurar a necessidade das organizações a se moverem da gestão de custos para a gestão estratégica de custos.

\subsection{ANÁLISE DA CADEIA DE VALOR}

De acordo com Shank e Govindarajan (1997), a análise da cadeia de valor é a primeira condição para a implementação da GEC. A cadeia de valor de uma empresa compreende o conjunto de atividades criadoras de valor, inicia com as fontes mais básicas, ou seja, na origem da matéria-prima, passa pelos fornecedores de insumos e termina no momento da entrega do produto final ao consumidor. (PORTER, 1991; SHANK; GOVINDARAJAN, 1997).

A análise da cadeia de valor é a identificação e a exploração de ligações internas (cadeia de valor interna) e externas (cadeia de valor externa) da empresa, com o objetivo de fortalecer a posição estratégica escolhida. Para Hansen e Mowen (2003), esta exploração de ligações depende da identificação das atividades e da seleção daquelas que podem ser usadas para produzir (ou sustentar) uma vantagem competitiva e, em seguida, de uma análise sobre como custos e outros fatores não financeiros variam com a consideração de diferentes grupos de atividades. Este processo de seleção requer o conhecimento do custo e do valor de cada atividade, "porque os clientes finais em última instância pagam por todas as margens de lucro ao longo de toda a cadeia de valor". (HANSEN; MOWEN, 2003, p. 63). 
de análise estratégica mudou nas últimas décadas. Passou da empresa para a "família de negócios" (que inclui concorrentes e fornecedores) e, mais recentemente, para a "empresa ampliada", que inclui o cliente, em que se almeja alcançar a criação conjunta de experiências. Ainda para os autores, a competência dos consumidores é um ativo intangível e deve ser tratada como tal. Para prover a estabilidade e, ao mesmo tempo, adotar as mudanças necessárias, é preciso desenvolver um sólido conjunto de valores organizacionais.

Deste modo, uma empresa pode aumentar sua margem, não apenas pela abrangência da sua própria cadeia de valor, mas também pela compreensão de como as atividades de valor se encaixam nas cadeias de valor dos fornecedores e dos clientes. Uma vez identificadas, Hansen e Mowen (2001) sugerem a análise das atividades dentro da perspectiva da cadeia de valor estratégica, as quais se classificam como atividades organizacionais e atividades operacionais, e os custos dessas atividades, por sua vez, como direcionadores de custos organizacionais e operacionais.

\subsection{ANÁLISE DO POSICIONAMENTO ESTRATÉGICO}

O posicionamento estratégico é a forma pela qual a empresa pretende competir. Porter (1991) propôs uma tipologia composta por três estratégias genéricas que podem ser adotadas por uma organização: a) liderança no custo total; b) diferenciação; e c) enfoque. Para o autor, as empresas que utilizam uma (e apenas uma) das três estratégias apresentam melhor desempenho.

Contrariamente a esta posição, Hansen e Mowen (2001) asseveram que o posicionamento estratégico é o processo de seleção de uma combinação ótima das três abordagens estratégicas gerais de Porter (1991). Da mesma forma, Kaplan e Norton (1997) afirmam que uma estratégia que reflete a combinação delas pode ser definida, em que é necessário cumprir algumas etapas, como, por exemplo: selecionar os segmentos de mercado e clientes que a unidade de negócios pretende atender; identificar os processos internos críticos do negócio em que a unidade precisa se destacar para entregar as proposições de valor aos clientes nos segmentos-alvo do mercado; e, por fim, selecionar as capacidades individuais e organizacionais necessárias para os objetivos internos, financeiros 
e dos clientes.

Contudo, Shank e Govindarajan (1997) abordam apenas duas formas de posicionamento estratégico: diferenciação do produto e liderança em custo. Segundo os autores, no posicionamento de liderança de custo, existe maior importância do gerenciamento dos custos para obtenção de dados para o planejamento, avaliação de desempenho e definição de preço. É necessário controle orçamentário, tanto de curto como de longo prazo, para o planejamento e o controle dos custos. Além disso, os custos devem ser analisados frente aos dados dos concorrentes. Porter (1999) complementa que uma empresa só consegue superar em desempenho os seus concorrentes quando estabelece uma diferença preservável, ao proporcionar maior valor para os clientes.

Em geral, uma postura de escolha estratégica pelo menor custo tem implicações sobre toda a cadeia de valor do produto. Estratégias deste tipo, geralmente, são adotadas por empresas que fabricam produtos mais básicos (commodities) e com pouco uso de tecnologia. Dessa forma, estratégias de baixo custo, normalmente, apresentam linhas de produtos restritas com o objetivo de baixar os custos por meio de economias de escala. Além disso, em empresas com posicionamento em liderança de custos, deve ser dada atenção especial ao gerenciamento da curva de experiência.

A continuidade da estratégia implica uma visão mais dinâmica e sistêmica da competição. A empresa precisa continuar na busca pela eficácia operacional e, ao mesmo tempo, esforçar-se constantemente para ampliar a singularidade e o fortalecimento da compatibilidade entre as atividades. (PORTER, 1999). Por fim, cabe salientar que a estratégia não é estática, sobretudo se houver grande mudança estrutural no setor. As novas posições estratégicas de uma empresa podem derivar das mudanças que ocorrem no setor e que são exploradas com mais facilidade pelos novos entrantes, pois estão desonerados dos fardos da história (imagem, clientes e valores).

Santos (2004) pesquisou os efeitos decorrentes da aplicação dos conceitos da gestão estratégica de custos sobre os resultados apurados nos modelos gerenciais de uma empresa de terceirização de serviços de instalação e manutenção de redes de telecomunicações e suas consequências sobre a mensuração e desempenho por atividade. 
Concluiu que, para a manutenção de diferenciais competitivos sustentáveis, é indispensável a construção de um sistema de custeio adequado à realidade da empresa e que não há a possibilidade de construção de uma modelo de gerenciamento estratégico de custos sem o suporte de um sistema eficiente, de forma que os direcionadores de custos também podem ser obtidos e controlados por estes sistemas a partir de indicadores de atividades específicos.

\subsection{ANÁLISE DOS DIRECIONADORES DE CUSTOS}

De acordo com Shank e Govindarajan (1997), os direcionadores estratégicos de custos diferem, de forma significativa, dos direcionadores de custos da contabilidade tradicional, em que basicamente o volume de produção é considerado como a única causa da variação dos custos da empresa. Assim, os autores observam que explicar o comportamento dos custos com base em apenas um direcionador é limitado.

A simples alocação racional dos custos não é mais suficiente, pois isto já é feito pelos tradicionais sistemas de custos. Conforme os princípios da GEC, torna-se necessário o entendimento de que os custos são causados por diversos fatores, e estes nem sempre podem ser mensurados monetariamente. (SHANK; GOVINDARAJAN, 1997). A administração de direcionadores de custos organizacionais e operacionais para criar resultados de redução de custos é uma entrada importante na análise da cadeia de valor quando a liderança em custos é enfatizada. (HANSEN; MOWEN, 2003).

Para Porter (1989, p. 62), os principais condutores de custos são "economias de escala, aprendizagem, o padrão de utilização da capacidade, elos, inter-relações, integração, momento oportuno, políticas discricionárias, localização e fatores institucionais". Dentre os condutores de custos citados pelo autor, nenhum deles é capaz de determinar, de forma isolada, a posição de custos de uma empresa. Em geral, eles interagem de forma dinâmica e dependem do tipo de empresa, do setor a que atende ou outras particularidades, os quais influenciam de forma significativa as suas atividades.

Dessa forma, os executivos precisam se conscientizar das limitações de se adotar 
um único direcionador de custos. Shank e Govindarajan (1997) lembram que outros fatores (além do volume) interferem no direcionamento dos custos de produção das empresas. Verifica-se, então, que ambas as correntes - a Cadeia de Valor de Porter (1989), bem como a Gestão Estratégica de Custos de Shank e Govindarajan (1997) - convergem para a necessidade de considerar, ao mesmo tempo, mais de um elemento direcionador dos custos na empresa. Logo, cada organização deve descobrir quais são os seus principais elementos causadores de custos e, desta forma, discutir as estratégias mais apropriadas em função da sua estrutura de custos.

De acordo com Riley (1987 apud SHANK; GOVINDARAJAN, 1997) os direcionadores de custos se dividem em duas categorias: custos estruturais e direcionadores de execução. Shank e Govindarajan (1997) asseveram que, no primeiro grupo, a empresa possui cinco escolhas estratégicas diferentes - escala, escopo, experiência, tecnologia e complexidade - tendo em vista sua estrutura econômica subjacente, para direcionar sua posição de custos para qualquer grupo de produtos. "Cada direcionador estrutural envolve escolhas realizadas pela empresa que direcionam o custo do produto." (SHANK; GOVINDARAJAN, 1997, p. 23). A segunda categoria de direcionadores de custos está mais ligada ao desempenho da empresa. Segundo Shank e Govindarajan (1997), os direcionadores de execução são aqueles determinantes da posição de custos de uma empresa, que dependem de sua capacidade de executar e do seu desempenho, quais sejam: gestão participativa, gestão da qualidade total, utilização da capacidade, eficiência do layout das instalações, configuração do produto e exploração de ligações com fornecedores e/ou clientes.

A contabilidade gerencial promoveu, ao longo das últimas décadas, importantes progressos para as empresas, mas não é suficiente para atender a atual necessidade do ambiente, cada vez mais complexo. Por isso, o reconhecimento de diversos fatores como causadores dos custos é um passo coerente e que pode trazer benefícios, não somente para uma unidade de negócios, mas para a cadeia de valor global do produto ou serviço. Segundo Shank e Govindarajan (1997), o campo da análise de custos está mudando em direção aos direcionadores de execução porque as análises baseadas em direcionadores estruturais são, 
com muita frequência, ultrapassadas. Desta forma, na GEC, há uma tendência para a valorização mais intensa dos direcionadores de execução. Assim, as habilidades de execução são as maiores responsáveis para o sucesso das organizações, pois demonstram a capacidade da empresa em executar os direcionadores estruturais.

\section{METODOLOGIA DA PESQUISA}

Quanto aos objetivos, pode-se definir o presente trabalho como descritivo; quanto aos procedimentos, como estudo de caso; e, quanto à abordagem do problema, como predominantemente qualitativo. O instrumento de pesquisa é composto por entrevistas com aplicação de questionários semiestruturados, e a técnica aplicada na interpretação dos dados é a análise de conteúdo.

A pesquisa se caracteriza como um estudo de caso, na medida em que, na concepção de Yin (2001, p. 32), é uma investigação empírica sobre "um fenômeno dentro do seu contexto da vida real, especialmente quando os limites entre o fenômeno e o contexto não estão claramente definidos". Em complementação, Triviños (1987) afirma que o estudo de caso é um estudo profundo, que possibilita o conhecimento da realidade. Contudo, a maior dificuldade que se pode constatar no estudo de caso, segundo Goode e Hatt (1979), é a resposta do pesquisador, que chega a ter a falsa sensação de certeza sobre suas próprias conclusões.

A pesquisa é descritiva, na medida em que, segundo Babbie (1998), detém-se nas características de determinada população ou fenômeno e pode estabelecer relações entre variáveis. Envolve técnicas padronizadas de coleta de dados como a entrevista e a observação participante.

A natureza do estudo é predominantemente qualitativa, pois envolve aspectos não quantificáveis (MINAYO, 1994). O estudo tem orientação à análise dos fatores intervenientes no processo de implementação de um sistema de gestão estratégica de 
custos em uma empresa estatal de energia elétrica brasileira, considerando-se a cultura, as regras do setor, a legislação que trata das estatais, o suporte tecnológico e o direcionamento estratégico. Segundo Richardson (1989), a abordagem qualitativa se justifica por ser uma forma adequada para o entendimento da natureza de um fenômeno social.

Para a realização do estudo, utilizam-se fontes de dados primários e secundários. Na coleta de dados primários, foram utilizadas técnicas de observação indireta e entrevistas. O questionário foi elaborado com perguntas fechadas e abertas. As perguntas fechadas foram destinadas à caracterização do entrevistado e à identificação da sua percepção quanto ao nível de aderência dos fatores intervenientes do modelo proposto por Shank e Govindarajan ao modelo adotado pela Eletrosul. Logo, ao final do questionamento sobre cada fator interveniente, solicitou-se ao entrevistado o fornecimento de uma posição quanto à aderência deste fator à realidade percebida na empresa. Já as perguntas abertas foram destinadas ao aprofundamento da opinião do entrevistado sobre o tema do estudo.

As entrevistas ocorreram de forma individual, com o uso de gravador. "No contato direto, o pesquisador pode explicar e discutir os objetivos da pesquisa e do questionário, responder dúvidas que os entrevistados tenham em certas perguntas." (RICHARDSON, 1989, p. 196). A entrevista dirigida se desenvolve com base em perguntas precisas, pré-formuladas e com uma ordem estabelecida, em que o entrevistador dirige o processo.

Com o objetivo de analisar a ação dos fatores intervenientes, foram realizadas 13 entrevistas com pessoas nos três níveis hierárquicos: estratégico, tático e operacional. Os entrevistados são empregados que atuam na área de gestão de custos e empregadosgestores selecionados por exercerem funções que estabelecem relação direta com a gestão de custos ou com a implementação da GEC na Eletrosul. A identificação desta relação se baseou na descrição das atribuições de suas respectivas áreas conforme estabelecido no Manual de Organização da Empresa. (ELETROSUL, 2009b). Portanto, foram entrevistados apenas empregados efetivos da empresa, a fim de minimizar a interferência do componente político-partidário.

Além das entrevistas, foi realizada uma pesquisa documental e bibliográfica para 
a coleta de dados secundários. Gil (1993) argumenta que a pesquisa bibliográfica é elaborada por meio de material já publicado, constituído principalmente por livros, artigos de periódicos e, atualmente, com material disponibilizado da Internet. A pesquisa documental é elaborada com base em materiais que não receberam tratamento analítico ou estão em estado original.

Os dados coletados nas entrevistas foram analisados e interpretados com 0 propósito de se estabelecer a comparação entre as informações encontradas nos documentos formais com o efetivamente praticado na empresa e, também, para contrastar as opiniões dos três níveis hierárquicos sobre os mesmos fatores intervenientes. Assim, os dados foram analisados por intermédio da técnica de análise de conteúdo que, segundo Triviños (1987), é utilizada para estudar o material qualitativo. Tal procedimento pode ser definido como o conjunto de técnicas de análise de comunicações obtidas por meio de métodos sistemáticos e objetivos de descrição do conteúdo das mensagens, cujos indicadores, qualitativos ou não, permitem a inferência de conhecimentos relativos às condições de produção e recepção das mensagens.

Após a análise, realizou-se a triangulação dos dados que compõem os diversos autores, o marco teórico e as entrevistas e/ou questionários feitos nos três níveis hierárquicos, com o objetivo de alcançar a máxima amplitude das descrições, realizando-se a composição de dados nas entrevistas, nas observações e na pesquisa bibliográfica. Portanto, procurou-se identificar as similaridades, convergências e divergências entre os depoimentos.

\section{ANÁLISE DOS RESULTADOS}

O modelo do setor elétrico alterou a regulamentação e inseriu algum grau de competição, além do apelo pela modicidade tarifária. Isso ensejou a necessidade de adaptação das empresas do setor, em especial das públicas, que precisam lidar com suas limitações para se tornarem competitivas, ágeis, enxutas e eficientes. Santos (2004) verificou 
essa mesma situação quando estudou o setor de telecomunicações, que também é um setor regulado e teve que aplicar estratégias agressivas. Contudo, analisando-se o histórico, os relatórios e os documentos internos da Eletrosul, identificou-se que nem sempre os objetivos estratégicos adotados resultaram de um processo de planejamento formal, com estratégias deliberadas. Muitas vezes, eram respostas ao ambiente e surgiam de forma emergente.

A Eletrosul (2007b) apresentou, em seu Plano Estratégico, a intenção de buscar um crescimento sustentável nas atividades de geração e de transmissão. Esta estratégia está detalhada no Plano de Expansão Empresarial, que determina ações que a colocam em prática. (ELETROSUL, 2009c). Pela perspectiva de Shank e Govindarajan (1997), esta abordagem está classificada como "construir", ou seja, implica adotar uma meta de aumento da fatia de mercado. Todos os entrevistados, nos três níveis hierárquicos, estavam conscientes desta estratégia empresarial.

No referido Plano Estratégico (ELETROSUL, 2007b), a empresa afirma que a obtenção de custos competitivos é condição necessária para a realização dos seus objetivos, o que permite sucesso nos leilões de energia e redução do impacto negativo da Revisão Tarifária. Foi nesta direção que se definiu a ação de implementação da GEC. Na perspectiva de Porter (1991), esta estratégia se classifica como posicionamento estratégico baseado em Liderança no Custo Total.

Para os entrevistados do nível estratégico e tático, as decisões estratégicas dos gestores estão alinhadas com as definições e orientações do Plano Estratégico, conforme depoimentos por meio de entrevistas. Isto demonstra que as questões definidas no Plano de Expansão (construir), como a obtenção de custos competitivos (liderança em custos), também são objetivadas. No entanto, os entrevistados do nível operacional não sabiam avaliar o alinhamento das decisões. Além disso, afirmaram desconhecer o processo de tomada de decisão e, até mesmo, o plano de ação da empresa.

Além do seu próprio Plano Estratégico, a Eletrosul também segue as determinações da controladora, a Eletrobrás (2009), exteriorizadas no Contrato de Metas e Desempenho Empresarial (CDME). Por tais metas, percebe-se que a holding também está 
preocupada em ser competitiva e controlar os custos, pois definiu metas que representam uma escala decrescente de custos. Dentre os entrevistados, nove, nos três níveis hierárquicos, citaram espontaneamente a necessidade e os esforços que estão fazendo para atender ao $\mathrm{CMDE}$, e isto evidencia o alinhamento e o esforço conjunto para o alcance dos objetivos empresariais.

Segundo Shank e Govindarajan (1997), para praticar o custo estratégico é essencial que se entenda toda a cadeia de geração de valor e que se analise a posição de cada um dos agentes, de forma a aproveitar as oportunidades de ligações externas para a redução dos custos ou para o aumento da diferenciação, ou ambos, e se posicionar em relação à concorrência. Portanto, é preciso avaliar os outros sistemas que se relacionam com o sistema empresa, na geração de sinergia para alcance de objetivos comuns.

Nas entrevistas realizadas e na análise documental, percebe-se que os gestores da Eletrosul concordam que é preciso ampliar o horizonte de análise, ou seja, ter uma visão ampliada do sistema empresa, com o entendimento da interação necessária com diversos fatores e agentes, de forma a atingir seus objetivos e gerar vantagem competitiva sustentável para a organização no longo prazo. Para tanto, Shank e Govindarajan (1997) recomendam que a contabilidade gerencial se adapte para atender às necessidades da gestão estratégica e dar apoio à tomada de decisão e ao alcance dos objetivos estratégicos. No entanto, de acordo com os entrevistados, a contabilidade gerencial da Eletrosul ainda não está preparada.

Além disso, dadas as particularidades do setor elétrico e da empresa objeto do estudo, alguns pontos da teoria precisam ser adaptados para tornar possível a sua implementação, o que corrobora os estudos de Souza, Silva e Pitz (2010), em que verificaram uma preferência pelo uso de práticas tradicionais de gestão de custos. Dada esta característica, existe um forte distanciamento em relação ao aplicado na literatura e o uso da gestão estratégica de custos nas organizações, como no caso da Eletrosul.

O sistema de gestão de custos da empresa utiliza a metodologia de custeio baseado em atividades. Um entrevistado do nível operacional relata que o custeio por atividades é hoje o que melhor se ajusta à situação da empresa. No entanto, os 
entrevistados admitem que a análise e o gerenciamento dos custos ainda carecem de melhorias. Um ponto que merece destaque é a dificuldade de comunicação entre os níveis hierárquicos, o que contrasta com a pesquisa de Gusmão e Almeida (2008).

Por fim, a despeito do Plano Estratégico que determina a implementação da GEC ter sido aprovado em 2007, este ainda não foi plenamente incorporado pela Eletrosul. Para a compreensão de suas causas, faz-se necessário uma análise dos principais temas e das particularidades da empresa objeto do estudo.

\subsection{ANÁLISE DA CADEIA DE VALOR DA ELETROSUL}

Segundo Shank e Govindarajan (1997), a análise da cadeia de valor é a primeira chave para a implementação da GEC e, também, a forma mais significativa para a exploração da vantagem competitiva. O Quadro 1 apresenta os fatores intervenientes considerados necessários para a construção e adoção da cadeia de valor, bem como uma síntese da realidade de cada um deles na Eletrosul e a percepção dos diferentes níveis hierárquicos.

Quadro 1 - Fatores intervenientes da cadeia de valor da Eletrosul

\begin{tabular}{|l|l|l|}
\hline \multicolumn{3}{|c|}{ Cadeia de Valor } \\
\hline Fatores intervenientes & Síntese da Eletrosul & \multicolumn{1}{|c|}{$\begin{array}{c}\text { Percepção dos níveis } \\
\text { hierárquicos }\end{array}$} \\
\hline $\begin{array}{l}\text { Identificação da cadeia } \\
\text { de valor do setor e } \\
\text { atribuição de custos, } \\
\text { receitas e ativos às } \\
\text { atividades de valor. }\end{array}$ & $\begin{array}{l}\text { A Eletrosul já identificou sua cadeia de valor interna e } \\
\text { externa e selecionou os processos que agregam valor. } \\
\text { Essa cadeia ainda é explorada parcialmente. No } \\
\text { entanto, ainda tem algumas dificuldades para atribuir } \\
\text { custos, receitas e ativos aos processos críticos, pois } \\
\text { essa ação ainda não foi implementada. }\end{array}$ & $\begin{array}{l}\text { Osternatágico e tático } \\
\text { percebem bem as ligações } \\
\text { ainda não faz este tipo de } \\
\text { análise. }\end{array}$ \\
\hline $\begin{array}{l}\text { Diagnóstico de } \\
\text { direcionadores de custo } \\
\text { regulando cada } \\
\text { atividade de valor. }\end{array}$ & $\begin{array}{l}\text { Os direcionadores de custos ainda estão mais } \\
\text { vinculados à contabilidade gerencial. Não foram } \\
\text { identificados direcionadores para cada processo } \\
\text { crítico. Para gerenciá-los, é necessário primeiro } \\
\text { conhecer o custo de cada processo. }\end{array}$ & $\begin{array}{l}\text { Todos os níveis concordam } \\
\text { que este diagnóstico ainda } \\
\text { não foi realizado. }\end{array}$ \\
\hline $\begin{array}{l}\text { Desenvolvimento de } \\
\text { vantagem competitiva } \\
\text { sustentável por meio de } \\
\text { um melhor controle dos } \\
\text { direcionadores de } \\
\text { custos ou } \\
\text { reconfiguração da } \\
\text { cadeia de valor. }\end{array}$ & $\begin{array}{l}\text { Em um ambiente regulado, fica difícil reconfigurar a } \\
\text { cadeia de valor, pois as relações externas são regidas } \\
\text { por legislação e contratos padrões. Os direcionadores } \\
\text { de custos da empresa ainda precisam ser mais bem } \\
\text { definidos. O benchmark começou a ser desenvolvido } \\
\text { no final de 2009 e ainda não está plenamente } \\
\text { implantado de modo a permitir a análise em relação } \\
\text { aos concorrentes. }\end{array}$ & $\begin{array}{l}\text { Todos os níveis concordam } \\
\text { que esta análise ainda não } \\
\text { foi realizada. }\end{array}$ \\
\hline
\end{tabular}

Fonte: Elaborado pelos autores, 2011.

R. eletr. estrat. neg., Florianópolis, v.5, n.1, p. 137-166, jan./abr. 2012 
A Eletrosul explora o potencial da sua cadeia de valor interna e externa, de forma a obter vantagem competitiva. Para tal, faz a análise das ligações e desenvolve práticas de gestão, como a que faz com clientes. Sua análise ainda é parcial, mas já desenvolve ações no sentido de propiciar a ampliação do seu horizonte, por exemplo, melhorando a ligação com fornecedores. A cadeia de valor não pode ser reconfigurada dada à forte regulamentação do setor. Não se atribuem custos aos processos, mas isso é feito por meio das atividades (custeio por atividades).

Logo, para dar sustentação à situação apresentada no Quadro 1, apresenta-se o relato da percepção dos níveis operacional e estratégico. O entrevistado do nível operacional afirma que "não é feita análise de custo por processo, nem são consideradas informações relacionadas a ligações com fornecedores e clientes. O foco da análise de custo é interno. $\mathrm{O}$ custeio é baseado por atividades, mas mesmo assim tem limitações (...)". Já o entrevistado do nível estratégico diz que "a Eletrobrás está promovendo reuniões para discutir a gestão por processos e a forma de análise de seus indicadores de desempenho. Os processos devem estar alinhados às estratégias da empresa".

Portanto, com o desenvolvimento da cadeia de valor, a Eletrosul pode contribuir para o fortalecimento do seu posicionamento estratégico e o alcance das suas estratégias de expansão (construir) e de custos competitivos (liderança em custos), cujo posicionamento se apresenta na análise a seguir.

\subsection{ANÁLISE DO POSICIONAMENTO ESTRATÉGICO DA ELETROSUL}

O posicionamento estratégico é a forma pela qual a empresa pretende competir e é a segunda chave para a implementação da GEC, na concepção de Shank e Govindarajan (1997). Para Porter (1991), o posicionamento estratégico deve estar baseado em uma tipologia composta por três estratégias genéricas: liderança no custo total, diferenciação e enfoque (ou focalização). Autores como Hansen e Mowen (2001), Shank e Govindarajan (1997), Kaplan e Norton (1997) acreditam que é possível haver uma combinação ótima dessas estratégias. 
Porter (1986) afirma que uma indústria (setor) passa pelas seguintes fases ou estágios: introdução, crescimento, maturidade e declínio. O setor elétrico brasileiro está em crescimento para atender à demanda de infraestutura necessária ao crescimento do país. A Eletrosul possui a missão de construir, o que, segundo Shank e Govindarajan (1997), é comum em empresas que se encontram no estágio de crescimento do ciclo de vida do produto. Para o atendimento desta missão, a empresa definiu a estratégia de liderança no custo total.

Porter (2002) apresenta duas opções para uma empresa ser mais rentável que os seus concorrentes: ter preços mais elevados ou custos mais baixos, além de oferecer produtos de qualidade e valores compatíveis. No entanto, a Eletrosul, por estar em um ambiente regulado, não pode elevar os preços, nem negociar livremente com seus clientes. Então, resta a opção de aumentar a quantidade de ativos novos e reduzir custos. Esta redução de custos se justificava por três motivos: a) aumentar a rentabilidade média por meio de ativos novos; b) ter a competitividade necessária para vencer leilões de energia e adquirir novos empreendimentos; e c) reduzir o impacto negativo do processo de Revisão Tarifária.

O posicionamento estratégico muda para se adequar ao tipo de missão adotada pela empresa, que, por sua vez, guarda relação com a fase do ciclo de vida. Para a Eletrosul, o alcance do objetivo de expansão dos seus ativos (missão de construir) implica a condição de ter custos competitivos (liderança em custo total) para ser competitiva e obter sucesso nos leilões de energia. No Quadro 2, apresenta-se o resumo dos fatores intervenientes para a análise do posicionamento estratégico, recomendados por Shank e Govindarajan (1997) para uma empresa que adota a posição de liderança em custos, como no caso da Eletrosul. 
Quadro 2 - Fatores intervenientes relativos ao posicionamento estratégico da Eletrosul

\begin{tabular}{|c|c|c|}
\hline \multicolumn{3}{|c|}{ Posicionamento Estratégico } \\
\hline $\begin{array}{c}\text { Fatores } \\
\text { Intervenientes }\end{array}$ & Síntese da Eletrosul & $\begin{array}{l}\text { Percepção dos níveis } \\
\text { hierárquicos }\end{array}$ \\
\hline $\begin{array}{l}\text { Desenvolvimento } \\
\text { de economia de } \\
\text { escala de produção }\end{array}$ & $\begin{array}{l}\text { Foco na expansão dos negócios de geração e de transmissão. } \\
\text { Objetivo de reduzir a idade média dos ativos, pois muitos } \\
\text { estavam depreciados e com rentabilidade baixa, e aumentar } \\
\text { a receita. }\end{array}$ & $\begin{array}{l}\text { Os três níveis } \\
\text { hierárquicos } \\
\text { concordam. }\end{array}$ \\
\hline $\begin{array}{l}\text { Controle dos } \\
\text { efeitos da curva de } \\
\text { experiência }\end{array}$ & $\begin{array}{l}\text { Desenvolvimento de um programa de Gestão do } \\
\text { Conhecimento e Programa de Repasse do Conhecimento dos } \\
\text { aposentáveis. Esta é uma tentativa de gerenciar custo } \\
\text { invisível, com a perda do conhecimento, semelhante ao que } \\
\text { aconteceu na década de 1990, com a perda de conhecimento } \\
\text { devido à privatização de parte da empresa. }\end{array}$ & $\begin{array}{l}\text { Os três níveis } \\
\text { hierárquicos têm a } \\
\text { mesma percepção. }\end{array}$ \\
\hline Controle de custos & $\begin{array}{l}\text { O orçamento é considerado uma ferramenta de controle. } \\
\text { Importância do planejamento do custo para definição do } \\
\text { preço. Falha no planejamento dos empreendimentos está } \\
\text { reduzindo a taxa interna de retorno planejada. Controle } \\
\text { dificultado pela tecnologia do sistema de informação e } \\
\text { cultura organizacional. Não é realizado controle do custo do } \\
\text { concorrente. }\end{array}$ & $\begin{array}{l}\text { Os três níveis } \\
\text { hierárquicos têm a } \\
\text { mesma percepção. }\end{array}$ \\
\hline $\begin{array}{l}\text { Minimização de } \\
\text { gastos para } \\
\text { agregar valor ao } \\
\text { produto }\end{array}$ & $\begin{array}{l}\text { Investimento em tecnologias que agregam valor e reduzem } \\
\text { custos, tais como linhas de transmissão telecontroladas, } \\
\text { teleconferência para reuniões e treinamentos entre áreas } \\
\text { descentralizadas. A redução de custos gera vantagem } \\
\text { competitiva, mas o foco está na qualidade do produto } \\
\text { principal, instalações disponibilizadas. }\end{array}$ & $\begin{array}{l}\text { Somente o nível } \\
\text { estratégico tem esta } \\
\text { percepção. Os níveis } \\
\text { tático e operacional } \\
\text { não se } \\
\text { manifestaram. }\end{array}$ \\
\hline
\end{tabular}

Fonte: Elaborado pelos autores, 2011.

Entre os entrevistados do nível estratégico, percebeu-se a posição da empresa pela busca da qualidade do seu principal produto - instalações disponibilizadas -, mesmo que isso não gere maximização de resultado. Isso contraria o que prega o fator de minimização de gastos para agregar valor ao produto, afinal o posicionamento estratégico está baseado em liderança no custo.

Portanto, esta prática precisa ser mais bem estudada para que se encontre um equilíbrio entre o investimento realizado e o seu retorno. Além disso, identificou-se outro tipo de investimento em tecnologias que agregam valor, mas que, ao mesmo tempo, reduzem custos operacionais, tais como linhas de transmissão telecontroladas, teleconferência para reuniões e treinamentos entre áreas descentralizadas. A opinião do gestor de nível estratégico, a respeito destas novas tecnologias, é de que: 
[...] quanto mais tecnologia usarmos em termos de teleassistência, em termos de videoconferência, sistemas de supervisão remota e no monitoramento de imagens, mais reduzirão os custos operacionais da empresa. Ele é um redutor dos custos operacionais e é um elemento que agrega qualidade ao sistema.

\subsection{ANÁLISE DOS DIRECIONADORES DE CUSTOS DA ELETROSUL}

A análise dos direcionadores de custos é a terceira e última chave para a implementação da GEC, de acordo com Shank e Govindarajan (1997). Para os autores, a simples alocação racional dos custos não é mais suficiente para o atendimento das necessidades dos gestores da organização, pois isso já é feito pelos sistemas de custos. É preciso entender que os custos são causados por diversos fatores, os quais nem sempre podem ser mensurados monetariamente. O Quadro 3 apresenta os fatores intervenientes, considerados pelos autores como necessários para a análise dos direcionadores de custos, com uma síntese da realidade de cada um na empresa e a percepção dos níveis hierárquicos.

Quadro 3 - Fatores intervenientes relativos aos direcionadores de custos da Eletrosul.

\begin{tabular}{|l|l|l|}
\hline \multicolumn{1}{|c|}{ Fatores Intervenientes } & \multicolumn{1}{|c|}{ Direcionadores de Custos } \\
\hline $\begin{array}{l}\text { Identificação de } \\
\text { direcionadores que } \\
\text { representem escolhas } \\
\text { estruturais ligadas ao custo do } \\
\text { produto }\end{array}$ & $\begin{array}{l}\text { Existem direcionadores, mas não são usados } \\
\text { de forma sistematizada e nem estão } \\
\text { vinculados diretamente a nenhuma atividade } \\
\text { de valor ou processo crítico. }\end{array}$ & $\begin{array}{l}\text { Os três níveis hierárquicos } \\
\text { concordam. } \\
\text { hierárquicos }\end{array}$ \\
\hline $\begin{array}{l}\text { Identificação de } \\
\text { direcionadores que } \\
\text { representem habilidades de } \\
\text { execução ligada ao } \\
\text { desempenho da empresa }\end{array}$ & $\begin{array}{l}\text { Existem direcionadores usados para avaliar o } \\
\text { desempenho da gestão da empresa e } \\
\text { monitorar o seu posicionamento estratégico. }\end{array}$ & $\begin{array}{l}\text { Eles são monitorados pelo } \\
\text { nível estratégico e operacional não } \\
\text { os conhecem. }\end{array}$ \\
\hline $\begin{array}{l}\text { Definição de uma estrutura de } \\
\text { análise específica para cada } \\
\text { direcionador de modo a } \\
\text { compreender a posição } \\
\text { competitiva da empresa }\end{array}$ & $\begin{array}{l}\text { Não há uma estrutura de análise para os } \\
\text { direcionadores estruturais. Os direcionadores } \\
\text { de execução são monitorados pela } \\
\text { metodologia do balanced scorecard, no nível } \\
\text { estratégico. Contudo, a comparação destes } \\
\text { direcionadores com os concorrentes não é } \\
\text { realizada. }\end{array}$ & $\begin{array}{l}\text { Os níveis tático e } \\
\text { operacional não souberam } \\
\text { prestar informações sobre }\end{array}$ \\
\hline
\end{tabular}

Fonte: Elaborado pelos autores, 2011.

Em relação aos três fatores intervenientes expostos no Quadro 3, nos itens 2 e 3, 
existem opiniões divergentes entre os diferentes níveis hierárquicos e, portanto, carecem de maior atenção. No que tange à identificação de direcionadores que representam habilidades de execução ligada ao desempenho da empresa, o gestor de nível estratégico (que monitora este quesito) afirma que:

[...] são usados direcionadores de execução. A manutenção faz análises do layout, verifica o custo de alocar equipes e equipamentos em diversos lugares. Também se usa direcionadores para avaliar a cadeia, tais como a satisfação dos clientes e os indicadores de desempenho de processos.

Já no nível tático, os gestores conhecem as ações, mas não os gerenciam. Segundo um dos entrevistados, "existem indicadores adotados pela Eletrosul que direta ou indiretamente apresentam o desempenho da empresa em relação ao seu custo e seu posicionamento estratégico, mas eles não são gerenciados pela nossa área".

Nos aspectos relacionados à definição de uma estrutura de análise específica para cada direcionador, de modo a compreender a posição competitiva da empresa, item 3 , o nível estratégico (único que soube prestar esclarecimentos) afirma que "a análise dos custos dos concorrentes não é muito relevante porque a Eletrosul não tem concorrente. Ninguém pode colocar uma linha ao lado da nossa. A concorrência é restrita aos leilões. Além disso, é muito difícil fazer, ninguém abriria a informação".

Portanto, para que a Eletrosul implemente completamente os três fatores intervenientes, é necessário encontrar formas de concorrer de modo eficaz no seu segmento, no sentido de torná-la uma prestadora de serviço de custo baixo. Precisa compreender os direcionadores estruturais e de execução do comportamento de custos dos grandes itens de custos de seus produtos/serviços e gerenciar estes direcionadores melhor do que os seus concorrentes. Além disso, precisa encontrar formas de usar as ligações da cadeia de valor onde está inserida para potencializar o seu posicionamento estratégico no sentido de gerar vantagem competitiva. 


\section{CONCLUSÕES E RECOMENDAÇÕES}

A apuração dos custos surgiu em atendimento às necessidades da administração das organizações e, desde a época da Revolução Industrial, vem sendo aperfeiçoada como parte do sistema de informações gerenciais. Em termos práticos, a empresa pode realizar uma melhor estruturação dos seus sistemas de custos, o que, consequentemente, pode lhe conferir uma vantagem competitiva sustentável de longo prazo. Neste sentido, com a implementação da GEC, a empresa objeto de estudo pretende criar alicerces para que a visão individualista seja transformada em uma visão compartilhada acerca dos processos organizacionais, com a compreensão de que cada etapa do trabalho pertence a um contexto mais amplo e que impacta na cadeia de valor.

$\mathrm{Na}$ realidade, a gestão estratégica de custos da Eletrosul se encontra parcialmente implementada, de maneira que a sua fundamentação, sua sistematização e seu aperfeiçoamento ainda acontecem paralelos ao processo, o que foi evidenciado pelas entrevistas com os três níveis hierárquicos da organização. Embora haja perspectivas promissoras para a implementação do novo modelo de gestão de custos, não houve, até o momento da pesquisa, transformações reais voltadas à adoção dos conceitos e fundamentos que balizam tal modelo. Apesar da crença compartilhada sobre a eficácia do modelo, o insuficiente comprometimento dos empregados e chefias no processo, além da ausência de programas de treinamentos específicos e falhas na comunicação, parecem contribuir para a não efetivação do novo modelo.

Contudo, os entrevistados afirmam que há a necessidade de criação de uma área organizacional que faça a gestão e a análise dos custos, a qual precisa focar sua atenção no atendimento das necessidades estratégicas e dos tomadores de decisão, diferentemente da atual estrutura, focada no atendimento das questões legais e dos órgãos regulamentadores.

Também foi identificado que, de maneira geral, a tecnologia da informação tem gerado dificuldades tanto para o processamento dos dados pelo nível operacional quanto para acesso às informações e acompanhamento dos custos pelo nível gerencial. Percebe-se 
que há pontos para melhorar na atual concepção do processo de comunicação na empresa objeto do estudo, conforme identificado nos relatos dos três níveis hierárquicos. A comunicação é vertical e obedece a posições hierárquicas formalmente definidas, de acordo com o organograma. Esta dificuldade transcende a questão da gestão estratégica de custos, cuja melhoria do seu processo e gerenciamento é de grande valia para o planejamento estratégico, já que a comunicação é estratégica em qualquer segmento do mercado ou ramo de atividade.

A primeira condição para a implementação da GEC - a Análise da Cadeia de Valor - está parcialmente atendida na Eletrosul. A cadeia de valor interna e externa e suas respectivas ligações foram identificadas e analisadas. A análise, porém, fica prejudicada por ainda não ter custos, receitas e ativos atribuídos aos processos críticos, mas isso é feito por meio das atividades (custeio por atividades), o que já permite uma análise parcial. Os direcionadores de custos de cada processo crítico, nos moldes propostos por Shank e Govindarajan (1997), ainda não foram totalmente diagnosticados pela empresa. Porém, a contabilidade deve se estruturar para atender a esta necessidade dos gestores. Existe uma dificuldade de reconfiguração da cadeia de valor dada a forte regulamentação do setor elétrico brasileiro. Portanto, seu esforço está centrado em desenvolver todo seu potencial da cadeia de valor e gerenciar seus direcionadores de custos melhor que seus concorrentes, o que pode fortalecer seu posicionamento estratégico e o alcance de suas estratégias de expansão (construir) e de custos competitivos (liderança em custos).

Os entrevistados dos níveis estratégico e tático percebem bem as ligações externas e internas da cadeia de valor. Muitas vezes, utilizam informações externas para a tomada de decisões. Por outro lado, o nível operacional ainda não faz este tipo de análise. Logo, este primeiro fator pode ser considerado aderente ao modelo, apesar de alguns aspectos necessitarem de melhorias de forma a potencializar o seu desempenho. Houve consenso apenas no que se refere aos direcionadores de custos vinculados às atividades de valor, pois todos concordam que este diagnóstico ainda não foi realizado.

A segunda condição para implementação da GEC - a Análise do Posicionamento Estratégico - é a que concentra os fatores intervenientes que estão mais estruturados na 
empresa, da forma como propõem o modelo teórico de Shank e Govindarajan (1997). A empresa definiu seu posicionamento em liderança no custo total. Percebe-se que há alinhamento vertical e horizontal em torno do foco na expansão dos ativos de transmissão e geração e do aumento da participação do mercado de energia, cujo alinhamento gera sinergia para o alcance de tal objetivo. No entanto, precisa promover ações que a tornem competitiva para obter sucesso nos leilões de energia. Entre tais ações, está o gerenciamento do conhecimento da força de trabalho, a melhoria do controle e gerenciamento dos custos, para garantir a rentabilidade planejada, e o desenvolvimento de estudos para minimização dos gastos para agregar valor ao produto principal.

Os três níveis hierárquicos têm, praticamente, a mesma percepção quanto ao foco na expansão, a necessidade de gerenciamento da curva de experiência (mas nem todos conhecem as práticas que estão em andamento para atendimento deste fator) e da importância do controle de custos. Estes três fatores estão aderentes ao modelo e contribuem de forma positiva para a implementação da GEC, pois existem clareza e consenso na estrutura horizontal e vertical quanto à importância do tema e das ações a serem praticadas. Quanto aos gastos para agregar valor ao produto, somente o nível estratégico soube dar informações, o que demonstra a necessidade de disseminação deste item, que pode estar associado a características culturais do passado.

A última condição para a implementação da GEC - a Análise dos Direcionadores de Custos - concentra os fatores intervenientes menos aderentes ao modelo teórico. Não é realizada uma análise sistematizada dos direcionadores estruturais, e os poucos analisados não estão vinculados às atividades de valor para que se possa avaliar o desempenho em relação ao custo dos produtos. Por outro lado, existem direcionadores de execução usados para avaliar o desempenho da gestão da empresa e monitorar o seu posicionamento estratégico, analisados somente pelo nível estratégico, os quais não são analisados em relação ao concorrente.

Nenhum dos três níveis hierárquicos soube dar informações consistentes sobre estes direcionadores de custos. Entretanto, os entrevistados do nível estratégico afirmam que, no futuro, tais direcionadores devem ser desenvolvidos e relacionados aos processos 
considerados críticos pela organização. Estes fatores ainda não foram observados e, portanto, no momento atual, dificultam a implementação da análise dos direcionadores de custos e da gestão estratégica de custos na sua integralidade. No entanto, existe a perspectiva de implantação de ações na empresa que visam a desenvolver e a acompanhar os direcionadores de custos.

Assim, diante do exposto, percebe-se que a construção de um modelo de GEC pode estar longe de uma solução definitiva. Porém, um modelo de avaliação de custos, elaborado de acordo com os critérios e juízos de valor dos decisores da empresa, pode fornecer vantagem competitiva para a organização. Dessa forma, os gestores podem moldar seu próprio modelo de custos, dentro das necessidades específicas da organização. Dentro deste conceito, a empresa pode alcançar uma melhor estruturação dos seus sistemas de custos, conferindo-lhe vantagem competitiva sustentável de longo prazo.

Em última análise, reduzir os gastos nas empresas do setor elétrico pode significar redução da tarifa e, consequentemente, proporcionar uma menor conta de luz para os usuários, ou, ainda, gerar melhores resultados para que se possam realizar maiores investimentos e, assim, prestar um serviço mais adequado ao consumidor. Deste modo, alternativas que promovam um melhor desempenho dessas empresas são essenciais para a sociedade. Mais do que isso, pode-se tratar a questão como um ato de responsabilidade na gestão pública.

Em termos de recomendações para a elaboração de futuros trabalhos, sugeremse estudos que contemplem outras abordagens da gestão estratégica e da gestão de custos que não foram analisadas nesta pesquisa. O aperfeiçoamento do modelo de gestão estratégica de custos depende do avanço nas pesquisas e, ainda, da verificação de outras variáveis para agregar ao modelo e que não foram consideradas nesta pesquisa. 


\title{
THE IMPLEMENTATION PROCESS OF THE STRATEGIC MANAGEMENT ACCOUNTING IN A STATE ELECTRIC POWER COMPANY
}

\begin{abstract}
The present study aims to investigate the level of model adherence of Strategic Management Accounting (GEC) practiced by a stated-owned company of electric power to the model proposed by Shank and Govindarajan, from the managers and employees perspective. Ten factors were considered, internal and external to the organization, composed by the combination of three subjects: value chain analysis, strategic positioning analysis and costs drivers analysis. The study has descriptive characteristics and a qualitative nature, carried out through a case study in which data collection relies on the use of semistructured interviews, survey and participant observation. The study was conducted in Eletrosul Centrais Elétricas S.A, in the "management of the GEC process" area. For this, it was performed a comparation between the content of the information gathered in formal documents and the practical process (identified through the interviews). It was concluded that the GEC model has already been partially implemented in the company and there is some consensus among the respondents of the three hierarchical levels: i) the analysis of value chain focuses factors that facilitate and also hinder the implementation of the model; ii) analysis of strategic positioning focuses factors that are more structured; and iii) analysis of costs drivers focuses factors that hinder the full implementation of GEC.
\end{abstract}

Keywords: Strategic Management Accounting. Value chain. Electricity sector.

\section{REFERÊNCIAS}

BABBIE, E. The practice of social research. Belmont: Wadsworth Publishing Company, 1998. 
CINQUINI, L.; TENUCCI, A. Strategic Management Accounting: exploring distinctive features and links with strategy. 2007. MPRA Paper. Disponível em: <http://mpra.ub.unimuenchen.de/212/>. Acesso em: 5 abr. 2012.

ELETROBRÁS CENTRAIS ELÉTRICAS BRASILEIRAS S.A. Contrato de metas e desempenho empresarial que entre si fazem a Eletrosul Centrais Elétricas S.A. e a Centrais Elétricas Brasileiras S.A. Brasília, 2009. Documento interno.

ELETROSUL CENTRAIS ELÉTRICAS S.A. Guia de Gestão Empresarial. Florianópolis, 2007a. Documento interno.

Plano Estratégico 2007-2015. Florianópolis, 2007b. Documento interno.

Cartilha Eletrosul: nova energia para muitas gerações. Florianópolis, 2009a.

Documento interno.

. Manual de organização da empresa. Florianópolis, 2009b. Disponível em aplicativo de uso interno.

Plano de Negócio 2009-2018. Florianópolis, 2009c. Documento interno.

GIL, A. C. Como elaborar projetos de pesquisa. 3. ed. São Paulo: Atlas, 1993.

GOODE, W. J.; HATT, P. K. Métodos em pesquisa social. São Paulo: Companhia Ed. Nacional, 1979.

GUSMÃO, I. B.; ALMEIDA, L. B. de. A utilização dos custos no suporte às atividades de marketing: um estudo no setor hoteleiro de Curitiba e região metropolitana. In: CONGRESSO ANPCONT, 2., 2008, Salvador. Anais... Salvador: ANPCONT, 2008.

HANSEN, D. R.; MOWEN, M. M. Gestão de Custos: contabilidade e controle. São Paulo: Pioneira Thomson Learning, 2001.

KAPLAN, R. S.; NORTON, D. P. A estratégia em ação: balanced scorecard. 4. ed. Rio de Janeiro: Campus, 1997.

LANGFIELD-SMITH, L. Strategic management accounting: how far have we come in 25 years? Accounting, Auditing \& Accountability Journal, Sydney, v. 21, n. 2, p. 204-228, 2008.

MACHADO, E. A. et al. Estratégias e práticas de gestão de custos: investigação empírica na indústria da construção civil do estado do Paraná. In: CONGRESSO USP DE CONTROLADORIA E CONTABILIDADE, 8., 2008, São Paulo. Anais... São Paulo: USP, 2008.

MAHER, M. Contabilidade de custos: criando valor para a Administração. São Paulo: Atlas, R. eletr. estrat. neg., Florianópolis, v.5, n.1, p. 137-166, jan./abr. 2012 
O PROCESSO DE IMPLEMENTAÇÃO DA GESTÃO ESTRATÉGICA DE CUSTOS EM UMA EMPRESA ESTATAL DE ENERGIA ELÉTRICA

Sabrina Weiss Raupp - Altair Borgert - Patrícia Nunes - Mara Juliana Ferrari

2001.

MINAYO, M. C. de S. (Org.). Pesquisa social: teoria, método e criatividade. Petrópolis: Vozes, 1994.

NAKAGAWA, M. Gestão estratégica de custos: conceito, sistema e implementação JIT/TQC. São Paulo: Atlas, 2000.

PORTER, M. E. Estratégia competitiva: técnicas para análise de indústrias e da concorrência. 7. ed. Rio de Janeiro: Campus, 1986.

. Vantagem competitiva. 11. ed. Rio de Janeiro: Campus, 1989.

. Vantagem competitiva: criando e sustentando um desempenho superior. 3. ed. Rio de Janeiro: Campus, 1991.

. Como as forças competitivas moldam a estratégia. In: MONTGOMERY, C. A.;

PORTER, M. E. Estratégia: a busca da vantagem competitiva. Rio de Janeiro: Campus, 1998, p. 11-27.

. O que é estratégia? In: Porter, M. E. Competição = on competition: estratégias competitivas essenciais. Rio de Janeiro: Campus, 1999, p. 46-82.

A nova era da estratégia. In: JULIO, C. A.; SALIBI NETO, J. (Orgs.). Estratégia e

planejamento. São Paulo: Publifolha, 2002, p. 21-38. (Coletânea HSM Management)

PRAHALAD, C. K.; RAMASWAMY, V. Como incorporar as competências do cliente. HSM Management, Barueri, v. 4, n. 20, maio/jun., 2000.

RICHARDSON, R. J. Pesquisa Social: métodos e técnicas. 2. ed. São Paulo: Atlas, 1989.

SANTOS, J. L. dos; SCHMIDT, P.; PINHEIRO, P. R. Fundamentos da gestão estratégica de custos. São Paulo: Atlas, 2006.

SANTOS, L. S. Gestão estratégica de custos em empresas de terceirização de serviços de instalação e manutenção de redes de telecomunicações. 2004. 99 f. Dissertação (Mestrado em Economia com ênfase em Controladoria)-Universidade Federal do Rio Grande do Sul, Porto Alegre, 2004.

SHANK, J. K.; GOVINDARAJAN, V. A revolução dos custos: como reinventar e redefinir sua estratégia de custos para vencer em mercados crescentemente competitivos. 2. ed. Rio de Janeiro: Elsevier, 1997.

SOUZA, M. A. de.; SILVA, E. J.; PILZ, N. Estrutura e práticas de gestão estratégica de custos: um estudo em uma empresa multinacional brasileira. In: CONGRESSO USP DE

R. eletr. estrat. neg., Florianópolis, v.5, n.1, p. 137-166, jan./abr. 2012 
O PROCESSO DE IMPLEMENTAÇÃO DA GESTÃO ESTRATÉGICA DE CUSTOS EM UMA EMPRESA ESTATAL DE ENERGIA ELÉTRICA

Sabrina Weiss Raupp - Altair Borgert - Patrícia Nunes - Mara Juliana Ferrari

CONTROLADORIA E CONTABILIDADE, 10, 2010, São Paulo. Anais... São Paulo: USP, 2010.

TRIVIÑOS, A. N. S. Introdução à pesquisa em ciências sociais: a pesquisa qualitativa em educação. São Paulo: Atlas, 1987.

WRUBEL, Franciele et al. Uma proposta para a validação de categorias sobre gestão estratégica de custos. Revista Brasileira de Gestão de Negócios, São Paulo, v. 13, n. 40, p. 332-348, jul./set. 2011.

YIN, R. K. Estudo de caso: planejamento e métodos. Porto Alegre: Bookman, 2001. 